\title{
Does financial development reinforce ecological footprint in singapore? Evidence from ardl and bayesian analysis
}

Bui Hoang Ngoc

Ho Chi Minh City Open University

ashar awan ( $\square$ asharawan786@hotmail.com )

University of Azad Jammu and Kashmir https://orcid.org/0000-0002-9922-7795

\section{Research Article}

Keywords: Financial development, Ecological footprint, ARDL, Bayesian analysis, Singapore

Posted Date: November 1st, 2021

DOl: https://doi.org/10.21203/rs.3.rs-988321/v1

License: (c) (1) This work is licensed under a Creative Commons Attribution 4.0 International License.

Read Full License

Version of Record: A version of this preprint was published at Environmental Science and Pollution Research on November 25th, 2021. See the published version at https://doi.org/10.1007/s11356-02117565-5. 

SINGAPORE? EVIDENCE FROM ARDL AND BAYESIAN ANALYSIS

Bui Hoang Ngoc a \& Ashar Awan b,*

${ }^{a}$ Ho Chi Minh City Open University, Ho Chi Minh City, Vietnam

${ }^{\mathrm{b}}$ NisanTasi University, Graduate school, Turkey

8 Bui Hoang Ngoc

9 Finance, Economics and Management Research Group, Ho Chi Minh City Open University,

10 35-37 Ho Hao Hon Street, District 1, Ho Chi Minh City, Vietnam;

11 Email: ngoc.bh@ou.edu.vn

12 ORCID ID: 0000-0002-1892-985X

13 Ashar Awan

14 NisanTasi University, Graduate school, Turkey

15 University of Azad Jammu and Kashmir, Pakistan

16 Email: asharawan786@hotmail.com 
Singapore has been ranked in the most dynamic financial market and the highest ecological 21 deficit country, indicating that the trade-off hypothesis may exist. The main goal of the present study is to probe the impact of financial development, economic growth, and human capital on ecological footprint in Singapore from 1980 to 2016. The outcomes obtained from the Auto

24 Regressive Distributed Lag (ARDL) method have failed to provide a clear impact of financial sector 25 development on ecological footprint. However, the Bayesian analysis reveals that both financial 26 development and economic growth have a harmful influence on EF, while the impact of human 27 capital is beneficial. A theoretical conclusion derived is that monetary expansion policies should be associated with improving human capital to achieve the United Nations SDGs in the context of

29 Singapore. The findings of the study are of particular interest to policymakers for developing sound policy decisions for sustainable economic progress which is not at the cost of environment.

31 Keywords: Financial development; Ecological footprint; ARDL; Bayesian analysis; Singapore. JEL Classification Code: B26, Q01, Q28. 


\section{Introduction}

36 Climatic change is one of the biggest issues of the 21 st century and a topic of overwhelming interest among the research community, policymakers, and professionals in international organizations working for sustainable development (Bayar \& Maxim, 2020). Therefore, environmental protection is top priority of countries, particularly signatories of the Paris Agreement (Saud et al., 2020; Usman, Kousar, \& Makhdum, 2020). The biggest threat to the environment is the emission of Green House Gases (GHG) which causes an increase in the temperature of the earth and consequently disturbing ecological balance (Ahmed et al., 2019; Baloch et al., 2019). Although, $\mathrm{CO} 2$ emission is the major contributor of GHG and cause of climate change (Bilgili et al., 2021), however, anthropogenic actions particularly, fossil fuel based energy consumption, water waste management and production of fertilizers are causing damage to the ecosystem too. Earlier literature used the ecological footprints as a proxy of pressure on nature by human activities (AlMulali \& Ozturk, 2015). The ecological footprint is a comprehensive measure of pressure on the ecosystem due to various human activities (Ahmed et al., 2019).

While on the other side, keeping a equilibrium between economic growth and environmental damage is a key issue that policymakers are facing. Therefore, it is emphasized to keep the environmental consequences of growth policies (Adedoyin et al., 2021; Destek et al., 2018; Ozturk et al., 2016). In addition, factors that are essential for economic activities may or may not damage the eco-system. While human capital is regarded as an environment-friendly determinant of economic growth (Ahmed \& Le, 2021; Danish et al., 2019), financial sector development may (Saud et al., 2020) or may not (Shahbaz et al., 2013; Uddin et al., 2017) be harmful; there is a negative relation between financial sector development and pollution (Hashmi \& Alam, 2019; Meirun et al., 2021).

An efficient financial system contributes to economic growth, it enables people to buy houses, home appliances and automobiles, however, all this puts pressure on nature by increasing energy demand (Baloch et al., 2019). Furthermore, a financial development boosts investment in new plants and factories and consequently causes more water waste and pollution (Danish et al., 2018). However, financial development is also credited to reduce pollution by boosting investment in research and development of green technologies and energy-efficient machines (Shahbaz et al., 2016). Financial development serves as a strong policy tool for the government to control pressure on the environment. Government can use their influence on financial institutions on their credit provision to less polluting production activities. The financial sector can contribute to environmental protection by discouraging loans to those investment initiatives that produce massive 
pollution. In addition, investment in a green environmental project, loans to socially responsible firms, and credit to eco-friendly projects curb environmental degradation (Saud et al., 2020). Indisputably, financial sector development - the crucial factor for economic development - is associated with ecological quality through technique, scale and composition effects (Saud et al., 2020). However, findings of previous literature about the influence of financial sector development on the natural environment are mixed. On the one hand, literature reported the negative effect of financial development on EF; for instance, in a panel of 27 countries (Uddin et al., 2017), for China (Destek \& Sarkodie, 2019), for Malaysia (Furuoka, 2015); for Nigeria (Omoke et al., 2020). On the other hand other studies reported a positive influence of financial development on EF for instance, (Usman, Kousar, \& Makhdum, 2020) for a panel of 20 highest economies, (Mrabet \& Alsamara, 2017) for Qatar and (Godil et al., 2020) for Turkey. Interestingly, Singapore is a country with rapid economic growth, industrialization and structural change experience (Katircioğlu, 2014; Tan et al., 2014). Though the country is small in size 721 $\mathrm{km} 2$, however, it faces serious challenges of environmental pollution due to its dense population (Han, 2017). While the country has achieved enormous economic growth targets, the government of Singapore is much concerned about negative externalities such as risk to the environment (Ridzuan et al., 2017). Though the literature has been indicating the factors that put pressure on the raised to curb environmental pollution in a way that does not compromise on the economic growth of Singapore (Meirun et al., 2021).

Earlier literature on Singapore, examining the influence of financial sector development on EF is mixed. Some studies have found that financial development has increased EF (Destek \& Sarkodie, 2019) while the others show an opposite result (Naqvi et al., 2020; Saud et al., 2020). These contradictable findings have made a big question about the impact of financial development on EF in Singapore. Therefore, the purpose of this study is to further investigate the impact of financial development, economic growth, and human capital on EF in Singapore. However, our research differs from some previous studies in many ways. Firstly, previous studies have attempted to reveal the relationship between financial development and EF (Destek \& Sarkodie, 2019; Naqvi et al., 2020; Saud et al., 2020), but no studies included economic growth and human capital as control variables. Secondly, the impact of financial development on EF in Singapore has seemingly been ambiguous or even contradictable (Destek \& Sarkodie, 2019) found positive and; (M. T. I. Khan et al., 2019) insignificant and (Naqvi et al., 2020; Saud et al., 2020) negative. This ambiguity might be the result of the adoption of a frequentist inference, where parameters are unknown but fixed. Therefore, the present study applied two statistical inference types: frequentist inference and 
102 Bayesian inference, to provide probability interpretations of uncertainty and various effects of 103 financial development, economic growth, and human capital on EF.

104 The remainder of the study is presented as follows. The next section shows discussions related to relevant literature about the nexus between economic growth, financial development, pollution and human capital. This section is followed by Data and methodology section; after which, the results and findings are discussed in the "Empirical results and discussion" section. Lastly, the conclusion and policy recommendations based on empirical findings are presented in the "Conclusion and recommendations" section of the present study.

\section{Literature review}

\subsection{Financial development and EF}

The previous studies showed that there were two effects (technological effect and structural effect) of financial development on the environment, which means financial development may be beneficial or harmful to EF (Du et al., 2012; Saud et al., 2020). On the positive side, financial development boosts a country's financial structure, brings about financial channels, and attracts FDI, which in turn brings green-environment technology and fosters R\&D activities. As a result, global commercials, renewable energy, and technology advancements take place (Ahmed \& Le, 2021; Hsueh et al., 2013). Thus, financial development can improve environmental quality and decrease EF. On the other side, financial development can cause some scale effects of economy growth process. This point of view suggests that financial development could increase pollution which is caused by a high level of production of the economic-liberalization and higher energy consumption (Pazienza, 2015; Saud et al., 2020). According to (Ha et al., 2020), it is impossible to do economic and household activities without having a harmful influence on the natural ecosystem or environment.

Surprisingly, some empirical evidence supports both of these views based on the various development policies in each country and region. For instance, (Uddin et al., 2017) has applied the FMOLS and DOLS methods on the panel data of 27 leading world EF contributors from 1991 to 2012, and found that financial development has improved environmental quality by decreasing EF. Similarly, (Ahmed et al., 2019) has researched the connection between financial development and EF in Malaysia from 1971 to 2014. By adopting the Bayer-Hanck cointegration test and ARDL method, the outcomes have verified that financial development mitigates EF. (Omoke et al., 2020) has discovered the negative relationship between financial development and EF in Nigeria from 1971-2014. However, some studies have revealed a contrary result regarding the relationship between financial development and EF. (A. Khan et al., 2019) used five Belt and Road initiative 
136 (BRI) regions as a research context for the association between financial development and EF. They 137 used the augmented mean group (AMG), and the common correlated effect mean group (CCEMG) 138 approaches, then they found that EF has been fostered by financial development. In the same line, Usman et al. (2020) examined the 20 highest economies from 1995 to 2017. The results showed that financial development deteriorates environmental quality by increasing EF.

141 Godil et al. (2020) has also revealed a similar finding while testing the financial development - EF 142 nexus in Turkey between 1986 and 2018. A comprehensive literature review is presented in Table 1431.

\section{[Insert Table 1 here]}

\subsection{Economic growth, human capital, and EF}

There are evidences that financial development has a mutual relationship with economic growth and human capital (Hsueh et al., 2013). Economic growth (Ahmed, Zafar, et al., 2020; Alola et al., 2019; Usman, Kousar, Yaseen, et al., 2020) and human capital (Ahmed, Asghar, et al., 2020; Ahmed, Zafar, et al., 2020; Pata \& Caglar, 2021)) also have influences on EF. Accordingly, the investigation of the interaction between financial development and EF cannot provide a clear understanding without integrating human capital and economic growth.

Regarding the influence of economic growth on EF, most previous studies have demonstrated a trade-off between economic growth and EF since the rapid economic development has generated an unprecedented rise in energy demand, especially non-renewable energy ( $\mathrm{S}$. Nathaniel \& Khan, 2020; Udemba, 2020; Zafar et al., 2019). Furthermore, economic growth could facilitate urban migration and urbanization (Ahmad et al., 2019; S. Nathaniel et al., 2020; Wu et al., 2019), which means that it could certainly bring more pressures to urban infrastructure and ecological assets (Wu et al., 2019). However, there are also some studies suggesting that economic growth would improve EF in Africa and Europe (Usman, Kousar, Yaseen, et al., 2020) or Pakistan (Hassan et al., 2019).

Earlier literature also verifies that human capital mitigates environmental degradation, including EF (S. Nathaniel et al., 2020; S. Nathaniel \& Khan, 2020; Pata \& Caglar, 2021). Some scholars argue that human capital plays a significant role in fostering the adaption of technology change, so it could probably make sustainable growth (Ackah \& Kizys, 2015; Consoli et al., 2016). Moreover, human capital generates concerns about environmental problems (Adil, 2018; Asongu,

167 2018; Reynolds et al., 2010; Ulucak \& Li, 2020). Nevertheless, some studies, such as Croes et al. 168 (2021) and Ahmed et al. (2021), postulated that the beneficial outcomes of economic growth are insufficiently invested in human capital. As the result, human capital is not giving a significant 
effect on sustainable development (Dietz et al., 2007). In a recent study, Kassouri and Altintas (2020) indicated that human capital increases EF in MENA countries.

Besides, the impact of financial development on EF in Singapore is likely ambiguous or even contradictable (positive; Destek \& Sarkodie (2019); insignificant; Khan et al (2019); negative; Naqvi et al., (2020); Saud et al., (2020). In addition, Singapore has been ranked in the most dynamic financial markets in the world, but Singapore has also been listed in the highest ecological deficit countries. It implies that the trade-off hypothesis between financial development and ecological assets may be valid. Therefore, further investigation is necessary to provide probabilistic interpretations of model uncertainty and various influences of financial development, economic growth, and human capital on EF in Singapore.

\section{Data and methodology}

\subsection{Research model and data sources}

The role of financial development in economic growth is enormous, but it is undeniable to say that it could be harmful to natural ecosystems. Mutually, a rise in financial development brings about an increase in economic growth, which is directly proportional to EF. Besides, the study incorporated the human capital per person index (labelled, HC) as the control variable. According to Neumayer (2012), it is recognized that the concern on environmental quality in a high human capital country is better than in a low human capital country. Therefore, to assess the impact of financial development, economic growth, and human capital on EF in the case of Singapore, the study has followed the previous works of Baloch et al. (2019); Godil et al. (2020); Pata and Yilanci (2020); Saud et al. (2020); Chen et al. (2019); Usman et al. (2020); Zhao et al. (2019) to propose an initial model, detailed as:

$$
E F_{t}=\beta_{0}+\beta_{1} \cdot \ln F D_{t}+\beta_{2} \cdot \ln G D P_{t}+\beta_{3} \cdot H C_{t}+u_{t}
$$

where, $\beta_{1}, \beta_{2}, \beta_{3}$ are the long-run coefficients, while $t$ is the time (from 1980 to 2016), and $u$ is the error term. The EF variable is the ecological footprint index (units: gha per capita) collected from the Global Footprint Network. The FD variable is the financial development index (units: point) obtained from the International Monetary Fund (IMF).

In the study, we have used the financial development index as a proxy of financial development because it is a financial inclusion index, which is calculated based on the depth, access, and efficiency of financial institutions and financial markets of a country. The GDP variable is the income per capita (at a fixed price of 2010, units: U.S. dollar) abstracted by the World Bank, while the HC variable is the human capital per person index (units: point), quoted by the Federal 
Reserve Bank of St. Louis. A scale of zero to ten is applied for the human capital per person index, where zero is the lowest educated economy and 10 is the highest educated economy. In this work, two variables (FD and GDP) are used by following the logarithm to clarify smooth data, while the $\mathrm{EF}$ and $\mathrm{HC}$ variables have original data in use. The descriptive statistics of all variables are demonstrated in Table 2.

\section{[Insert Table 2 here]}

According to Table 2 the mean of Singapore's ecological footprint was 5.843 gha per capita, which is more than 2.8 gha per capita, the global average. Singapore has been listed in a group of countries where the ecological deficit is severe. Recently, Singapore has implemented many positive steps to reduce the ecological deficit situation and has made significant advancements in renewable energy technology. However, based on the International Energy Agency (IEA, 2018) data, Singapore has been ranked as $27^{\text {th }}$ out of 142 countries in terms of emissions per capita. Likewise, the mean of the lnGDP variable was 10.287, while the maximum value of the HC variable was 3.809. These data showed that Singapore had been a developed education system and high-income country.

\subsection{Methodology}

The estimated coefficients of Eq.(1) have only provided the long-run effects of financial development, economic growth, and human capital on ecological footprint. To analyze the short-run impacts, the study has applied the autoregressive distributed lag (ARDL) model, introduced by. The ARDL model has some advantages, such as: firstly, the estimated coefficients are unbiased and reliable in the case of small sample size; secondly, it could be applied in all three cases whether the variables are stationary at $\mathrm{I}(0), \mathrm{I}(1)$, or a mixture of both; thirdly, it provides both the short and long-run estimated coefficients; and fourthly, it could be used in two cases, where the cointegration among all variables exists or not (Nkoro \& Uko, 2016).

Therefore, (Eq.1) is written by the $\operatorname{ARDL}(\mathrm{p}, \mathrm{q})$ model, as follows:

$$
\Delta E F_{t}=\alpha_{0}+\beta_{1} \cdot E F_{t-1}+\beta_{2} \cdot \ln F D_{t-1}+\beta_{3} \cdot \ln G D P_{t-1}+\beta_{4} \cdot H C_{t-1}+
$$

$$
+\sum_{k=1}^{p-1} \alpha_{1 k} . \Delta E F_{t-k}+\sum_{k=0}^{q} \alpha_{2 k} . \Delta \ln F D_{t-k}+\sum_{k=0}^{q} \alpha_{3 k} . \Delta \ln G D P_{t-k}+\sum_{k=0}^{q} \alpha_{4 k} . \Delta H C_{t-k}+\varepsilon_{t}
$$

where: $\Delta$ is the first difference $\alpha_{1}, \alpha_{2}, \alpha_{3}, \alpha_{4}$ are coefficients of the short-run impacts $\varepsilon_{t}$ is the error 
To achieve the research objectives, our approach is summarized in a four-step process. First, 235 the ordinary least square (OLS) method is applied to Eq.(2) to estimate the long-run coefficients. 236 Second, the cointegration test is used to verify the integration among variables, in which the null hypothesis is stated: $\left(H_{0}: \beta_{1}=\beta_{2}=\beta_{3}=\beta_{4}=0\right)$ whilst the alternative hypothesis is written $238\left(H_{1}: \beta_{1} \neq \beta_{2} \neq \beta_{3} \neq \beta_{4} \neq 0\right)$. If the F-statistic value lies below the F-critical values, the null 239 hypothesis $4 \backslash$ is accepted accordingly. That means there is no cointegration among variables in the 240 long run. On the other hand, if the F-statistic value exceeds the F-critical value (the upper Bound value, I(1)), the null hypothesis is denied, and the Eq.(2) would be re-parameterized as an error correction model (ECM) as:

$$
\Delta E F_{t}=\alpha_{0}+\lambda \cdot E C M_{t-1}+\sum_{k=1}^{p-1} \alpha_{1 k} \cdot \Delta E F_{t-k}+\sum_{k=0}^{q} \alpha_{2 k} \cdot \Delta \ln F D_{t-k}+\sum_{k=0}^{q} \alpha_{3 k} \cdot \Delta \ln G D P_{t-k}+\sum_{k=0}^{q} \alpha_{4 k} . \Delta H C_{t-k}+\varepsilon_{t}
$$

(Equation.3)

where: $p, q$ are the lag order of each variable collected from the stationary test result. In Eq.(3), if the estimated coefficient of $\lambda$ is negative, and belongs [0;1] and significant, which means that the EF variable can itself re-adjust to long-run equilibrium point after short-run shocks caused by financial development, economic growth, or human capital.

Third, the major problem with the frequentist inference (e.g., ARDL model) is that estimated coefficients are unknown but fixed. More importantly, it is impossible to assess the link between two variables if the estimated coefficient is insignificant. To solve this case, the Bayesian inference approach through the integrated Markov chain Monte Carlo sample is applied to provide probabilistic interpretations of model uncertainty and to differ effects of financial development, economic growth, and human capital on EF. And in the last process, the modified Wald test introduced by Toda and Yamamoto (1995) is used to reveal the causal relationship between a pair of variables in our proposed model. The Toda and Yamamoto procedure is based on the vector autoregressive model (VAR). The causal relationship between the EF variable and lnFD variable is illustrated as follows:

$$
E F_{t}=\alpha_{0}+\sum_{i=1}^{h} \alpha_{1 i} \cdot E F_{t-i}+\sum_{j=h+1}^{p} \alpha_{2 i} \cdot E F_{t-j}+\sum_{i=1}^{h} \delta_{1 i} \cdot \ln F D_{t-i}+\sum_{j=h+1}^{p} \delta_{2 i} \cdot \ln F D_{t-j}+\mu_{1 t}
$$

$$
\ln F D_{t}=\beta_{0}+\sum_{i=1}^{h} \beta_{1 i} \cdot \ln F D_{t-i}+\sum_{j=h+1}^{p} \beta_{2 i} \cdot \ln F D_{t-j}+\sum_{i=1}^{h} \alpha_{1 i} E F_{t-i}+\sum_{j=h+1}^{p} \alpha_{2 i} \cdot E F_{t-j}+\mu_{2 t}
$$


where: $h$ is the optimal lag order of the VAR model, and $p=\left(h+d_{\max }\right)$, with $d_{\max }$ is the maximum lag order. According to Toda and Yamamoto (1995), the maximum of $\mathrm{d}_{\max }$ is 2, because if $d_{\max }>2$, the tests based on F-statistic are not reliable (Davoud et al., 2013; Nkoro \& Uko, 2016)

In Eq.(4), if an estimated coefficient of $\delta_{1}$ is significant, there will be a uni-directional causality running from financial development to ecological footprint. The advantage of the

Toda and Yamamoto (1995) procedure is beneficial in minimizing the risk of wrong determination of each variable's lag order and being able to be applied to the variable that is stationary at $\mathrm{I}(0)$ or $\mathrm{I}(1)$, or a combination of both cointegration and no-cointegration (Sankaran et al., 2019; Toda \& Yamamoto, 1995), or either of them.

\section{4}

\section{Empirical result and discussion}

\subsection{Empirical results}

Unit-root test

Nelson and Plosser (1982) suggested that it is necessary to check the stationary of time-series variable because most of the economic variable is non-stationary. Therefore, to avoid the empirical results being spurious, the three tests are employed, including the ADF test (Dickey \& Fuller, 1981), the PP test (Phillips \& Perron, 1988), and the GLS-ADF test proposed by Elliott et al. (1992) to confirm the stationary of each variable. Compared to the ADF test, the PP test is advantageous in accounting for the potential serial correlation and heteroskedasticity in the residuals. Similarly, the GLS-ADF test has an advantage in allowing the series to be stationary around a linear time trend; or it is to allow the series to be stationary around a possible nonzero mean with no time trend. Results of the stationary tests are presented in Table 3.

The stationary test presented in Table 3 provides evidence to reject the null hypothesis of a random walk with drift. More particularly, the $\operatorname{lnFD}$ variable remains stationary at $\mathrm{I}(0)$, while three variables (EF, lnGDP and $\mathrm{HC}$ ) remain unchanging at I(1) obtaining from three tests. No variable is stationary at I(2). In a brief conclusion, the condition in applying the ARDL model is satisfied accordingly (Nkoro \& Uko, 2016; Pesaran et al., 2001). Hence, the cointegration test could proceed for further analysis.

\section{Cointegration test}

The stationary test provided an inconsistent result of lag order between variables (mixture of $\mathrm{I}(0)$ and $\mathrm{I}(1))$. In the next step, it is necessary to check the long-run association of all variables. 
Hence, a new cointegration test, Bound-testing, has been employed to verify the cointegration in

296 financial development, economic growth, human capital, and ecological footprint in the case of 297 Singapore. The Bound-testing technique was proposed by Pesaran et al. (2001) with the null hypothesis quoted that $\mathrm{H}_{0}$ : No cointegration, against the alternative hypothesis $\mathrm{H}_{1}$ : there is cointegration between examined variables. The result of the Bound-testing is given in Table 4 . Accordingly, the F-statistic value $(=4.602)$ exceeds the F-critical value $(=4.35)$ at a significant level of 5\%. Likewise, the t-critical value (=-3.46) is higher than the t-statistic value $(=-3.671)$ at a significant level of $10 \%$. These results give evidence to reject the null hypothesis, which means that a long-run association between variables in our proposed model exists. Thus, Eq.(2) must be estimated by using the ECM model.

[Insert Table 4 here]

The short and long-run impacts by the error correction model

Another advantage of the ARDL model is that it could auto-select the optimal lag of each variable. Based on the Akaike Information Criterion (AIC), Schwarz Bayesian information criterion (SBIC), and Hannan-Quinn Information Criterion (HQIC), the empirical result in Table 5 showed that the optimal lag of EF and lnGDP variable is one, and lnFD variable is zero. Simultaneously, the obtained result also indicates that the volatility of current-period human capital is associated with two-period previous human capital.

\section{[Insert Table 5 here]}

After confirmation of cointegration, the error correction model is applied to study the impact of financial development, economic growth, and human capital on EF both in the short and longrun. The optimal lag of each variable is set to select the final ARDL specification. Applying to the data of Singapore, the best ARDL model is the ARDL $(1,1,0,0)$. The coefficients of the short and long-run impacts are shown in Table 6.

\section{[Insert Table 6 here]}

The empirical result showed in Table 6 indicates that the coefficient of CoinEq(-1) is negative and significant level at $1 \%(\lambda=-0.5647, \mathrm{p}$-value $=0.001)$. This finding supports that ecological footprint can re-adjust itself to the long-run equilibrium point after the short-run is suddenly affected by financial development, or economic growth, or human capital. Two years is the time needed for an adjustment $(=1 /|\lambda|)$. Table 6 also indicates that economic growth has a positive and significant impact on EF in the short and long-run. More specifically, an $1 \%$ rise in economic growth leads to a 4.39 gha per capita increase in the short-run ecological footprint and a 
long-run impact of economic growth on EF is greater than the short-run impact. Similarly, the estimated coefficient of the $\mathrm{HC}$ variable is -2.10 in the short-run and is -3.72 in the long-run, 330 respectively. These results imply that EF is affected by human capital in the case of Singapore. 331 However, contrary to the influence of economic growth, an increase in the human capital per person 332 induces a fall in ecological footprint. We believe that these fascinating findings could provide 333 Singapore policymakers more insights into sustainable development strategies. More details about 334 these findings will be discussed in the next section.

Nevertheless, the main aim of our research is to study the influence of financial development on EF in Singapore, which means that whether there is a trade-off between economic growth and environmental destruction. Unfortunately, the empirical outcome reveals that financial development has a positive impact on EF, but not yet significant. In the view of frequentist inference, the obtained outcome from the ECM approach has failed to demonstrate the influence of financial development on EF in the case of Singapore. Besides, the major diagnostic tests were used to confirm the above conclusions, including the heteroskedasticity test, the autocorrelation test, the distribution of residuals, and the functional form test. The results of diagnostic tests are given in the lowest in Table 6. Accordingly, the four tests have a p-value that is higher than 0.05 , and it is evident to reject the null hypothesis. Besides, the work has conducted the cumulative sum of recursive residuals (CUSUM) and the cumulative sum of squares of recursive residuals (CUSUMSQ) test to check the stability of the long-run coefficients and the short-run dynamics. Both CUSUM and CUSUMSQ lie within the Bound-critical value at the level of 5\% significance (see Figure 1a, 1b). When all diagnostic tests are satisfied, it is possible to conclude that our proposed model is stable and the obtained coefficients by the ECM approach are reliable.

\section{[Insert Figure 1a, and Figure 1b here]}

As the result, the failure in defining the effect of financial development on EF leads to difficulty makes some difficulties in suggesting efficient environmental protection policies. Therefore, the Bayesian analysis for the generalized linear model (GLM) was employed to reexamine the influence of financial development on EF in the context of Singapore.

Contrary to frequentist inference (i.e., where observed are assumed to be random and estimation parameters are unknown but have fixed quantities), the Bayesian inference assumes that the observed data is fixed, and estimation parameters are random (Bernardo \& Smith, 1994). The Bayesian analysis is based on the Bayes's rule and the posterior distribution results from using the prior information about model parameters with evidence from the observed data. An advantage of 
Bayesian analysis is that the Bayesian paradigm allows us to prove some probability statements, as a variable is likely or unlikely to impact on another, or the true value of a parameter falls into a certain interval with a pre-specified probability (Bernardo \& Smith, 1994; S.K.Thompson, 2012) . The specification of the Bayesian GLM regression is expressed as:

$$
y_{t}: N\left(\beta^{T} X_{t}, \delta^{2} I\right)
$$

where, $y_{t}$ is the ecological footprint drawn from normal Gaussian distribution, and $X_{t}$ is the matrix of the independent variables. $\beta^{T}$ denotes the transposed weight matrix, while $\delta^{2}$ is the variance and $I$ is the identity matrix, to give the model a multi-dimensional formulation. Generally, the prior distribution is defined as pre-existing information about model parameters and is often derived from theoretical or expert knowledge. Fortunately, Lemoine (2019) suggested that the estimated coefficients obtained from the OLS approach could be used in the case of weakly informative priors in Bayesian analysis. By this brilliant suggestion, the study adopts the estimated coefficient of variables from the OLS estimator to set the initial information of the Bayesian GLM model with assuming a normal distribution.

In the Bayesian GLM model, the posterior distribution of the estimated model parameters is generated from a probability distribution based on the prior information, observed data, and the outputs. The posterior distribution can be calculated as the following equation:

$$
P\left(\beta \mid y_{t}, X_{t}\right)=\frac{P\left(y_{t} \mid \beta, X_{t}\right) * P\left(\beta \mid X_{t}\right)}{P\left(y_{t} \mid X_{t}\right)}
$$

(Equation.7)

where, $P\left(y_{t} \mid \beta, X_{t}\right)$ is the likelihood of the data, and $P\left(\beta \mid X_{t}\right)$ denotes the prior probability information of the model parameters, while $P\left(y_{t} \mid X_{t}\right)$ represents the normalization constant. In this work, the adaptive random-walk Metropolis-Hastings algorithm was used to avoid the spurious convergence and provide probabilistic interpretations of model uncertainty and varying effects of financial development, economic growth, and human capital on EF. The result of Bayesian analysis is presented in Table 7.

\section{[Insert Table 7 here]}

The empirical outcome given in Table 7 reveals a positive effect of financial development and economic growth on EF, while the impact of human capital is negative. These results are in line with the coefficients obtained by the ECM model. More importantly, the linkage between financial development and ecological footprint has been established. Additionally, the acceptance rate of 0.37 is larger than the optimal acceptance rate of 0.234 (Gelman et al., 1997), whereas standard deviation values of the parameters are small, and the Monte Carlo chain standard errors (MCSE) are close to one decimal. Besides, the CUSUM plots of the parameters are jagged, not smooth, and crossing the 
$\mathrm{X}$-axis (see Figure 2). These obtained outcomes provide evidence to accept the Metropolis-Hastings algorithm and confirm the high accuracy of the parameter estimates (Cowles \& Carlin, 1996). Thus, Bayesian inference is valid.

\section{[Insert Figure 2 here]}

Contrary to frequentist inference, in Bayesian inference, 95\% credible intervals indicate which range the true value of a certain parameter belongs to. For example, the mean value of the financial development variable (lnFD) lies in an interval between -0.1329 and 0.3213 with a $95 \%$ probability. As expected, given probability, we may state that financial development has a strongly positive effect on ecological footprint with a 79\% probability (Block et al., 2011). The outcome is justified by the historical trend in money supply strategies and the serious ecological deficit situation in Singapore.

\section{The Granger causality test}

The ECM or GLM approach does not guide us about the causal relationship among the variables. In the final step, the Toda and Yamamoto (1995) procedure is applied to check the Granger causality between numbers of pairs of variables. The equation is used to test has been shown in Section 3, and the empirical result is given in Table 8 and Figure 3. According to Table 8, there is bi-directional causality between either economic growth (lnGDP) or human capital (HC) and ecological footprint (EF). At the same time, Figure 3 also indicated that (there if) unidirectional causality running lnGDP or EF or $\mathrm{HC}$ to financial development (lnFD), and running from $\mathrm{HC}$ to $\operatorname{lnGDP}$.

\section{[Insert Table 8 here]}

\section{[Insert Figure 3 here]}

\subsection{Discussion}

In frequentist inference, the obtained results demonstrate that the impact of financial development exerts an ambiguous effect in both the short-run and long-run, which is similar to the finding of (M. T. I. Khan et al., 2019). However, thanks to the Bayesian inference, the obtained outcomes have found a positive strongly influence of financial development on EF. With a 79\% probability, the study may conclude that an expansion financial development policy may be harmful to environmental quality in the context of Singapore. The finding is inconsistent with Saud et al (2020) and Naqvi et al (2020), who validate the negative impact of financial development on EF, while it is in line with Destek and Sarkodie (2019), who find that financial development increases EF in Singapore. More importantly, by applying Bayesian analysis, this work overcame the ambiguity found in a previous study (M. T. I. Khan et al., 2019). Thus, the study strongly confirmed 
that financial development plays a positive role in ecological footprint in Singapore. More broadly, the finding is consistent with many studies in various contexts, such as the research of (A. Khan et al., 2019) in the context of five Belt and Road initiative (BRI) regions, or (Godil et al., 2020) in Turkey. Nevertheless, it should be noted that some studies show contradicted results, such as (Uddin et al., 2017) on 27 leading world EF contributors, (Ahmed et al., 2019) on Malaysia, or (Omoke et al., 2020) on Nigeria (see also Table 1). In the context of Singapore, the study believes that financial development causes the scale effect by fostering economic liberalization and attract foreign direct investment (Pazienza, 2015; Saud et al., 2020). It means that an increase in financial development in Singapore leads to a rise in economic growth, high manufacture and energy consumption, especially non-renewable energy consumption due to economic-liberalization (Destek \& Sarkodie, 2019). This argument is consistent with some recent studies that ASEAN countries, including Singapore where non-renewableenergy has been largely used in many industries (Kongbuamai et al., 2020; S. Nathaniel \& Khan, 2020). Consequently, the financial development is both side-effects on) the increase of $\mathrm{CO}_{2}$ emissions, air and soil pollution, and on ultimate raise level of EF (Pazienza, 2015; Saud et al., 2020). As a result, the Singapore Government should considerably improve current policies regarding to financial development.

Both the ARDL and Bayesian analyses confirm that economic growth has a positive impact on EF (probability of $100 \%$ ). The finding is consistent with the trade-off theory and the empirical evidence between economic growth and EF since economic growth has increased energy (S. Nathaniel \& Khan, 2020; Udemba, 2020; Zafar et al., 2019), facilitation of urbanization (Ahmed et al., 2019; S. Nathaniel et al., 2020; Wu et al., 2019), and pressure on infrastructure and ecological assets(Sharma et al., 2020). Consequently, economic growth may break the balance in the biodiversity and increases EF, supported by the hypothesis of scale effect. As mentioned above, the increase in economic growth has generated a high level of non-renewable energy consumption in ASEAN countries, including Singapore (Kongbuamai et al., 2020; S. Nathaniel \& Khan, 2020). To maintain environmental quality, therefore, more effective economic growth strategies should be implemented.

Finally, human capital mitigates EF in both the short and long-run. The results are firmly validated by both the ARDL and Bayesian analyses with the probability of $100 \%$. The finding is justifiable since some scholars (for instance Nathaniel, 2020; Nathaniel et al., 2021; Pata and Caglar, 2021), who have discussed and empirically confirmed that human capital decreases EF. The results show that an increase in human capital leads to a corresponding rise in technological change adoption (Ackah \& Kizys, 2015; Consoli et al., 2016) as well as the awareness towards environmental quality problems(Adil, 2018; Asongu, 2018; Reynolds et al., 2010; Ulucak \& Li, 
2020); and thus, activities of environmental destruction should be reduced and sustainable development could be more promoted in Singapore. The findings also demonstrate the consistency with other contexts that emphasize the importance of human capital and have appropriate policies to foster human capital, such as the United States (Zafar et al., 2019), G7 countries (Ahmed, Asghar, et al., 2020; S. P. Nathaniel, 2020), Central and Eastern European Countries (Chen et al., 2019), among the others. The results likely prove how human capital is important and beneficial in the context of Singapore.

\section{Conclusion and policy implications}

\subsection{Conclusions}

We aim to uncover the true nature of the link between financial development and EF by incorporating economic growth and human capital as control variables. To achieve this purpose, the study used the ARDL approach to provide preliminary results, and then a Bayesian analysis was employed to provide more insightful outcomes. As expected, the Bayesian analysis enables us to firmly conclude that both financial development and economic growth have a positive impact on EF, while human capital decreases EF. These findings indicated that the trade-off hypothesis between financial development and ecological assets is valid. Hence, monetary expansion policies should be associated with improving human capital to achieve sustainable development goals in the context of Singapore.

The findings are undisputable in confirming that the current financial development policies of Singapore may threaten environmental quality. They should be better assimilated and used more effectively in policy instruments regarding financial development. As noted by the previous studies, financial development may improve environmental quality by boosting research and development and technological advancement (Ahmed et al., 2019). Thus, the Singapore Government should emphasize the vital role of the financial sector in providing funds for an adaption to use eco-friendly technologies in new ventures and also to in the existing businesses as a replacement of outdated technologies (Ahmed et al., 2019; Usman, Kousar, \& Makhdum, 2020). Furthermore, the study also recommends that Singapore Government should facilitate the optimal utilization of energy by boosting financial support for eco-friendly projects at a minimum interest rate (Usman, Kousar, \& Makhdum, 2020). Finally, additional funds should be allocated to support environmental policies as well as to raise the environmental awareness of residents (Pata \& Yilanci, 2020).

As economic growth increases EF in Singapore, the study suggests that the economic development policies should be focused on the decrease of non-renewable energy (S. Nathaniel \& Khan, 2020; Udemba, 2020; Zafar et al., 2019) and maintenance of balance between urbanization 
493

and the demand of ecological assets (Ahmed et al., 2019; S. Nathaniel et al., 2020; Wu et al., 2019). Thus, fostering the use of renewable and decreasing the use of non-renewable energy is utterly important. This can be implemented by using environmental taxes and subsidies for the removal of pollution technology. To balance the urbanization and biodiversity relationship, the establishment of smart cities seems to be the key solution (S. P. Nathaniel et al., 2021). Furthermore, the policies of financial development and economic growth in the context of Singapore should be integrated seamlessly to effectively foster environmental quality. More specifically, financial development should allocate more resources to developing and applying cleaner and more eco-friendly technologies. Novel technology is the key to remove "dirty" and obsolete technologies while fostering advanced and smart technologies in manufacturing and living.

Finally, human capital is an important factor of EF fall in Singapore. Thus, Singapore Government should generate a long and healthy living with a higher level of education and welfare/good living standards for residents (Türe \& Türe, 2021), since those are determinants of sustainable growth and development (Ackah \& Kizys, 2015; Consoli et al., 2016). Furthermore, policies to improve environmental problems awareness are also significant in improving environmental quality (Adil, 2018; Asongu, 2018; Reynolds et al., 2010; Ulucak \& Li, 2020). Similarly, the study should emphasize the urgency of the integration between financial development, economic growth and human capital policies since previous studies (Ahmed et al., 2021; Croes et al., 2021) have suggested insufficient resources resulting from financial development and economic growth in human capital lead to the role of this variable fell in improving biocapacity, and environmental quality, see also (Dietz et al., 2007). Furthermore, human capital development can be considered a base for screening and selecting appropriate imported technologies and R\&D (S. Nathaniel et al., 2020; Pata \& Caglar, 2021). Therefore, the work suggests that the Singapore Government should have a comprehensive vision about why financial development, economic growth and human capital influence on ecological footprint, and provided an integrated yet effective way to improve biocapacity, and environmental quality. 


\section{References}

Ackah, I., \& Kizys, R. (2015). Green growth in oil producing African countries: A panel data analysis of renewable energy demand. Renewable and Sustainable Energy Reviews, 50, 11571166.

Adedoyin, F. F., Nathaniel, S., \& Adeleye, N. (2021). An investigation into the anthropogenic nexus among consumption of energy, tourism, and economic growth: do economic policy uncertainties matter? Environmental Science and Pollution Research, 28(3), 2835-2847.

Adil, A. A. (2018). Could Human Development Be the Key to Environmental Sustainability? Leonardo, 51(2), 197-198.

Ahmad, M., Zhao, Z.-Y., \& Li, H. (2019). Revealing stylized empirical interactions among construction sector, urbanization, energy consumption, economic growth and $\mathrm{CO} 2$ emissions in China. Science of the Total Environment, 657, 1085-1098.

Ahmed, Z., Asghar, M. M., Malik, M. N., \& Nawaz, K. (2020). Moving towards a sustainable environment: the dynamic linkage between natural resources, human capital, urbanization, economic growth, and ecological footprint in China. Resources Policy, 67, 101677.

Ahmed, Z., \& Le, H. P. (2021). Linking Information Communication Technology, trade globalization index, and CO 2 emissions: evidence from advanced panel techniques. Environmental Science and Pollution Research, 28(7), 8770-8781.

Ahmed, Z., Wang, Z., Mahmood, F., Hafeez, M., \& Ali, N. (2019). Does globalization increase the ecological footprint? Empirical evidence from Malaysia. Environmental Science and Pollution Research, 26(18), 18565-18582.

Ahmed, Z., Zafar, M. W., \& Ali, S. (2020). Linking urbanization, human capital, and the ecological footprint in G7 countries: an empirical analysis. Sustainable Cities and Society, 55, 102064.

Ahmed, Z., Zhang, B., \& Cary, M. (2021). Linking economic globalization, economic growth, financial development, and ecological footprint: Evidence from symmetric and asymmetric ARDL. Ecological Indicators, 121, 107060.

Al-Mulali, U., \& Ozturk, I. (2015). The effect of energy consumption, urbanization, trade openness, industrial output, and the political stability on the environmental degradation in the MENA (Middle East and North African) region. Energy, 84, 382-389.

Alola, A. A., Bekun, F. V., \& Sarkodie, S. A. (2019). Dynamic impact of trade policy, economic growth, fertility rate, renewable and non-renewable energy consumption on ecological footprint in Europe. Science of the Total Environment, 685, 702-709. 
Asongu, S. A. (2018). CO 2 emission thresholds for inclusive human development in sub-Saharan Africa. Environmental Science and Pollution Research, 25(26), 26005-26019.

Baloch, M. A., Zhang, J., Iqbal, K., \& Iqbal, Z. (2019). The effect of financial development on ecological footprint in BRI countries: evidence from panel data estimation. Environmental Science and Pollution Research, 26(6), 6199-6208.

Bayar, Y., \& Maxim, A. (2020). Financial development and CO2 emissions in post-transition European Union countries. Sustainability, 12(7), 2640.

Bernardo, J. M., \& Smith, A. F. (1994). Bayesian theory: John Wily and Sons. New York.

Bilgili, F., Kuşkaya, S., Khan, M., Awan, A., \& Türker, O. (2021). The roles of economic growth and health expenditure on $\mathrm{CO} 2$ emissions in selected Asian countries: a quantile regression model approach. Environmental Science and Pollution Research, 1-24.

Block, J. H., Jaskiewicz, P., \& Miller, D. (2011). Ownership versus management effects on performance in family and founder companies: A Bayesian reconciliation. Journal of Family Business Strategy, 2(4), 232-245.

Chen, S., Saud, S., Saleem, N., \& Bari, M. W. (2019). Nexus between financial development, energy consumption, income level, and ecological footprint in CEE countries: do human capital and biocapacity matter? Environmental Science and Pollution Research, 26(31), 31856-31872.

Consoli, D., Marin, G., Marzucchi, A., \& Vona, F. (2016). Do green jobs differ from non-green jobs in terms of skills and human capital? Research Policy, 45(5), 1046-1060.

Cowles, M. K., \& Carlin, B. P. (1996). Markov chain Monte Carlo convergence diagnostics: a comparative review. Journal of the American Statistical Association, 91(434), 883-904.

Croes, R., Ridderstaat, J., Bąk, M., \& Zientara, P. (2021). Tourism specialization, economic growth, human development and transition economies: The case of Poland. Tourism Management, 82, 104181.

Danish, Hassan, S. T., Baloch, M. A., Mahmood, N., \& Zhang, J. (2019). Linking economic growth and ecological footprint through human capital and biocapacity. Sustainable Cities and Society, 47, 101516. https://doi.org/https://doi.org/10.1016/j.scs.2019.101516

Danish, Wang, B., \& Wang, Z. (2018). Imported technology and CO2 emission in China: Collecting evidence through bound testing and VECM approach. Renewable and Sustainable Energy Reviews, 82, 4204-4214. https://doi.org/https://doi.org/10.1016/j.rser.2017.11.002

Davoud, M., Behrouz, S. A., Farshid, P., \& Somayeh, J. (2013). Oil products consumption, electricity consumption-economic growth nexus in the economy of Iran: A bounds test cointegration approach. International Journal of Academic Research in Business and Social 
Sciences, 3(1), 353-367.

Destek, M. A., \& Sarkodie, S. A. (2019). Investigation of environmental Kuznets curve for ecological footprint: the role of energy and financial development. Science of the Total Environment, 650, 2483-2489.

Destek, M. A., Ulucak, R., \& Dogan, E. (2018). Analyzing the environmental Kuznets curve for the EU countries: the role of ecological footprint. Environmental Science and Pollution Research, 25(29), 29387-29396.

Dickey, D. A., \& Fuller, W. A. (1981). Likelihood ratio statistics for autoregressive time series with a unit root. Econometrica: Journal of the Econometric Society, 1057-1072.

Dietz, T., Rosa, E. A., \& York, R. (2007). Driving the human ecological footprint. Frontiers in Ecology and the Environment, 5(1), 13-18.

Du, L., Wei, C., \& Cai, S. (2012). Economic development and carbon dioxide emissions in China: Provincial panel data analysis. China Economic Review, 23(2), 371-384.

Elliott, G., Rothenberg, T. J., \& Stock, J. H. (1992). Efficient tests for an autoregressive unit root. National Bureau of Economic Research Cambridge, Mass., USA.

Furuoka, F. (2015). Financial development and energy consumption: Evidence from a heterogeneous panel of Asian countries. Renewable and Sustainable Energy Reviews, 52, 430 444.

Gelman, A., Gilks, W. R., \& Roberts, G. O. (1997). Weak convergence and optimal scaling of random walk Metropolis algorithms. The Annals of Applied Probability, 7(1), 110-120.

Godil, D. I., Sharif, A., Rafique, S., \& Jermsittiparsert, K. (2020). The asymmetric effect of tourism, financial development, and globalization on ecological footprint in Turkey. Environmental Science and Pollution Research, 27(32), 40109-40120.

Ha, N. M., Ngoc, B. H., \& McAleer, M. (2020). Financial Integration, Energy Consumption And Economic Growth In Vietnam. Annals of Financial Economics, 15(03), 2050010.

Han, H. (2017). Singapore, a garden city: Authoritarian environmentalism in a developmental state. The Journal of Environment \& Development, 26(1), 3-24.

Hashmi, R., \& Alam, K. (2019). Dynamic relationship among environmental regulation, innovation, $\mathrm{CO} 2$ emissions, population, and economic growth in OECD countries: A panel investigation. Journal of Cleaner Production, 231, 1100-1109.

Hassan, S. T., Xia, E., Khan, N. H., \& Shah, S. M. A. (2019). Economic growth, natural resources, and ecological footprints: evidence from Pakistan. Environmental Science and Pollution Research, 26(3), 2929-2938.

Hsueh, S.-J., Hu, Y.-H., \& Tu, C.-H. (2013). Economic growth and financial development in Asian 
countries: A bootstrap panel Granger causality analysis. Economic Modelling, 32, 294-301.

Kassouri, Y., \& Altıntaş, H. (2020). Human well-being versus ecological footprint in MENA countries: A trade-off? Journal of Environmental Management, 263, 110405.

Katircioğlu, S. T. (2014). Testing the tourism-induced EKC hypothesis: The case of Singapore. Economic Modelling, $\quad$ 41, 383-391. https://doi.org/https://doi.org/10.1016/j.econmod.2014.05.028

Khan, A., Chenggang, Y., Hussain, J., \& Bano, S. (2019). Does energy consumption, financial development, and investment contribute to ecological footprints in BRI regions? Environmental Science and Pollution Research, 26(36), 36952-36966.

Khan, M. T. I., Yaseen, M. R., \& Ali, Q. (2019). Nexus between financial development, tourism, renewable energy, and greenhouse gas emission in high-income countries: a continent-wise analysis. Energy Economics, 83, 293-310.

Kongbuamai, N., Bui, Q., Yousaf, H. M. A. U., \& Liu, Y. (2020). The impact of tourism and natural resources on the ecological footprint: a case study of ASEAN countries. Environmental Science and Pollution Research, 27(16), 19251-19264.

Lemoine, N. P. (2019). Moving beyond noninformative priors: why and how to choose weakly informative priors in Bayesian analyses. Oikos, 128(7), 912-928.

Meirun, T., Mihardjo, L. W. W., Haseeb, M., Khan, S. A. R., \& Jermsittiparsert, K. (2021). The dynamics effect of green technology innovation on economic growth and CO 2 emission in Singapore: New evidence from bootstrap ARDL approach. Environmental Science and Pollution Research, 28(4), 4184-4194.

Mrabet, Z., \& Alsamara, M. (2017). Testing the Kuznets Curve hypothesis for Qatar: A comparison between carbon dioxide and ecological footprint. Renewable and Sustainable Energy Reviews, $70,1366-1375$.

Naqvi, S. A. A., Shah, S. A. R., \& Mehdi, M. A. (2020). Revealing empirical association among ecological footprints, renewable energy consumption, real income, and financial development: a global perspective. Environmental Science and Pollution Research, 27(34), 42830-42849.

Nathaniel, S., Anyanwu, O., \& Shah, M. (2020). Renewable energy, urbanization, and ecological footprint in the Middle East and North Africa region. Environmental Science and Pollution Research, 1-13.

Nathaniel, S., \& Khan, S. A. R. (2020). The nexus between urbanization, renewable energy, trade, and ecological footprint in ASEAN countries. Journal of Cleaner Production, 272, 122709.

Nathaniel, S. P. (2020). Biocapacity, human capital, and ecological footprint in G7 countries: the moderating role of urbanization and necessary lessons for emerging economies. Energy, 
Nathaniel, S. P., Nwulu, N., \& Bekun, F. (2021). Natural resource, globalization, urbanization, human capital, and environmental degradation in Latin American and Caribbean countries. Environmental Science and Pollution Research, 28(5), 6207-6221.

Nelson, C. R., \& Plosser, C. R. (1982). Trends and random walks in macro-economic time series, journal of Monetary Economics. September, 10(2), 139-162.

Neumayer, E. (2012). Human development and sustainability. Journal of Human Development and Capabilities, 13(4), 561-579.

Nkoro, E., \& Uko, A. K. (2016). Autoregressive Distributed Lag (ARDL) cointegration technique: application and interpretation. Journal of Statistical and Econometric Methods, 5(4), 63-91.

Omoke, P. C., Nwani, C., Effiong, E. L., Evbuomwan, O. O., \& Emenekwe, C. C. (2020). The impact of financial development on carbon, non-carbon, and total ecological footprint in Nigeria: new evidence from asymmetric dynamic analysis. Environmental Science and Pollution Research, 27(17), 21628-21646.

Ozturk, I., Al-Mulali, U., \& Saboori, B. (2016). Investigating the environmental Kuznets curve hypothesis: the role of tourism and ecological footprint. Environmental Science and Pollution Research, 23(2), 1916-1928.

Pata, U. K., \& Caglar, A. E. (2021). Investigating the EKC hypothesis with renewable energy consumption, human capital, globalization and trade openness for China: Evidence from augmented ARDL approach with a structural break. Energy, 216, 119220. https://doi.org/https://doi.org/10.1016/j.energy.2020.119220

Pata, U. K., \& Yilanci, V. (2020). Financial development, globalization and ecological footprint in G7: further evidence from threshold cointegration and fractional frequency causality tests. Environmental and Ecological Statistics, 27(4), 803-825.

Pazienza, P. (2015). The relationship between CO2 and Foreign Direct Investment in the agriculture and fishing sector of OECD countries: Evidence and policy considerations. Intelektine Ekonomika, 9(1), 55-66.

Pesaran, M. H., Shin, Y., \& Smith, R. J. (2001). Bounds testing approaches to the analysis of level relationships. Journal of Applied Econometrics, 16(3), 289-326.

Phillips, P. C. B., \& Perron, P. (1988). Testing for a unit root in time series regression. Biometrika, 75(2), 335-346.

Reynolds, T. W., Farley, J., \& Huber, C. (2010). Investing in human and natural capital: An alternative paradigm for sustainable development in Awassa, Ethiopia. Ecological Economics, 69(11), 2140-2150. 
Ridzuan, A. R., Ismail, N. A., \& Che Hamat, A. F. (2017). Does foreign direct investment successfully lead to sustainable development in Singapore? Economies, 5(3), 29.

S.K.Thompson. (2012). Sampling (3rd ed.) (3rd ed.). Hoboken, N.J. : John Wiley \& Sons. Inc.

Sankaran, A., Kumar, S., Arjun, K., \& Das, M. (2019). Estimating the causal relationship between electricity consumption and industrial output: ARDL bounds and Toda-Yamamoto approaches for ten late industrialized countries. Heliyon, 5(6), e01904.

Saud, S., Chen, S., \& Haseeb, A. (2020). The role of financial development and globalization in the environment: accounting ecological footprint indicators for selected one-belt-one-road initiative countries. Journal of Cleaner Production, 250, 119518.

Shahbaz, M., Jam, F. A., Bibi, S., \& Loganathan, N. (2016). Multivariate Granger causality between $\mathrm{CO} 2$ emissions, energy intensity and economic growth in Portugal: evidence from cointegration and causality analysis. Technological and Economic Development of Economy, $22(1), 47-74$.

Shahbaz, M., Solarin, S. A., Mahmood, H., \& Arouri, M. (2013). Does financial development reduce $\mathrm{CO} 2$ emissions in Malaysian economy? A time series analysis. Economic Modelling, $35,145-152$.

Sharma, R., Sinha, A., \& Kautish, P. (2020). Examining the impacts of economic and demographic aspects on the ecological footprint in South and Southeast Asian countries. Environmental Science and Pollution Research, 27(29), 36970-36982.

Tan, F., Lean, H. H., \& Khan, H. (2014). Growth and environmental quality in Singapore: Is there any trade-off? Ecological Indicators, 47, 149-155. https://doi.org/https://doi.org/10.1016/j.ecolind.2014.04.035

Toda, H. Y., \& Yamamoto, T. (1995). Statistical inference in vector autoregressions with possibly integrated processes. Journal of Econometrics, 66(1-2), 225-250.

Türe, C., \& Türe, Y. (2021). A model for the sustainability assessment based on the human development index in districts of Megacity Istanbul (Turkey). Environment, Development and Sustainability, 23(3), 3623-3637.

Uddin, G. A., Salahuddin, M., Alam, K., \& Gow, J. (2017). Ecological footprint and real income: panel data evidence from the 27 highest emitting countries. Ecological Indicators, 77, 166175.

Udemba, E. N. (2020). A sustainable study of economic growth and development amidst ecological footprint: New insight from Nigerian Perspective. Science of the Total Environment, 732, 139270.

Ulucak, R., \& Li, N. (2020). The nexus between economic globalization and human development in 
Asian countries: an empirical investigation. Environmental Science and Pollution Research, 27(3), 2622-2629.

Usman, M., Kousar, R., \& Makhdum, M. S. A. (2020). The role of financial development, tourism, and energy utilization in environmental deficit: evidence from 20 highest emitting economies. Environmental Science and Pollution Research, 27(34), 42980-42995.

Usman, M., Kousar, R., Yaseen, M. R., \& Makhdum, M. S. A. (2020). An empirical nexus between economic growth, energy utilization, trade policy, and ecological footprint: a continent-wise

\section{Declarations}

\subsection{Ethics approval and consent to participate}

No human data is involved in this research.

\subsection{Consent for publication}

It is not applicable to this study, as there is no human data involved in it.

\subsection{Availability of data and materials}

The datasets/codes used and/or analyzed during the current study are available from the corresponding author on reasonable request.

\subsection{Competing interests}

The authors declare that they have no competing interests

\subsection{Funding}

There is not involvement of funding in this research. 


\section{$755 \quad$ 5.7. Authors' contributions}

756 BHN contributed in Writing - original draft, Conceptualization and Formal analysis and AA 757 performed Project administration, Writing - review \& editing. All authors read and approved the 758 final manuscript.

\section{5.8. Acknowledgements}

760 The authors acknowledge the feedback of the two reviewers.

\section{5.9. Authors' information (optional)}

762

763

764 
Figures
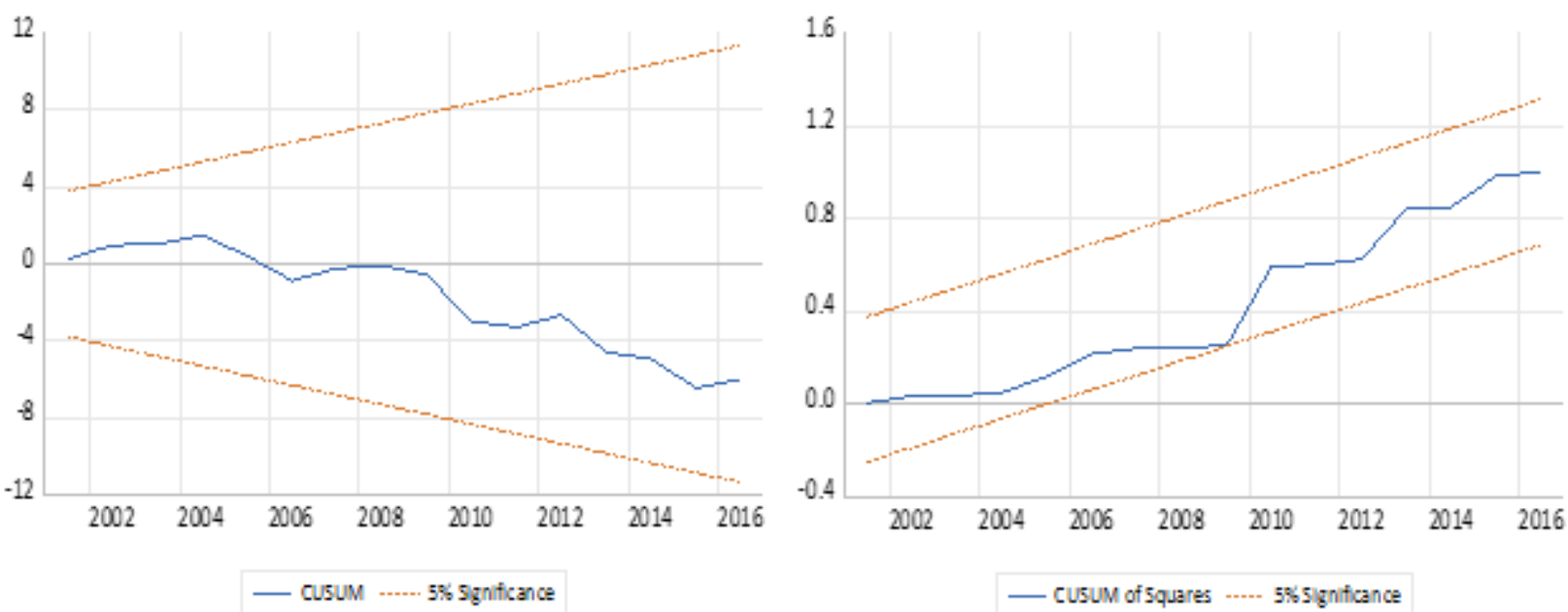

\section{Figure 1}

a. The CUSUM test and Figure b: The CUSUMSQ test

\section{Cusum plots}
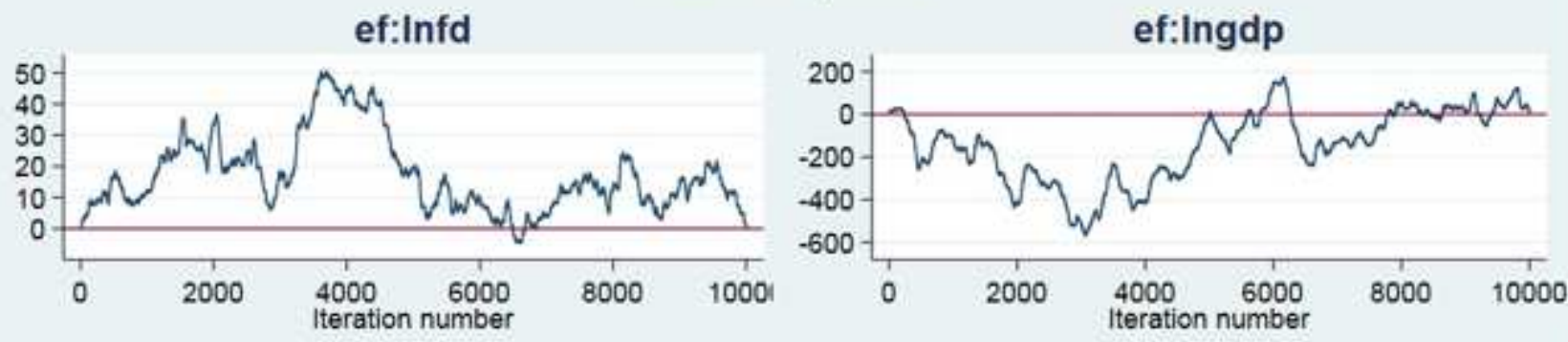

ef:hc

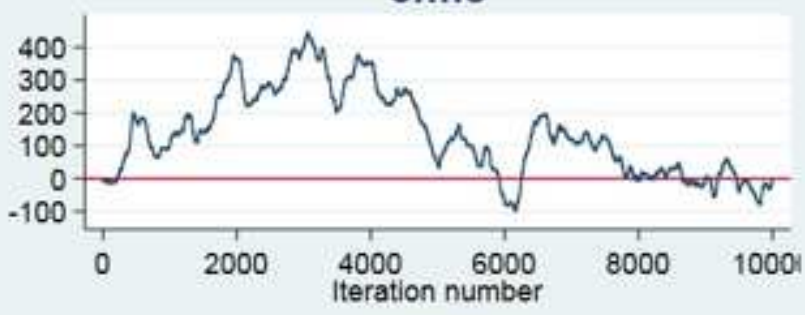

ef:_cons

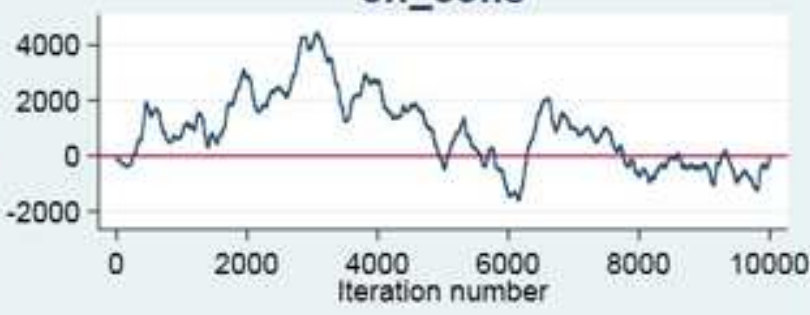

\section{e.ef:sigma2}

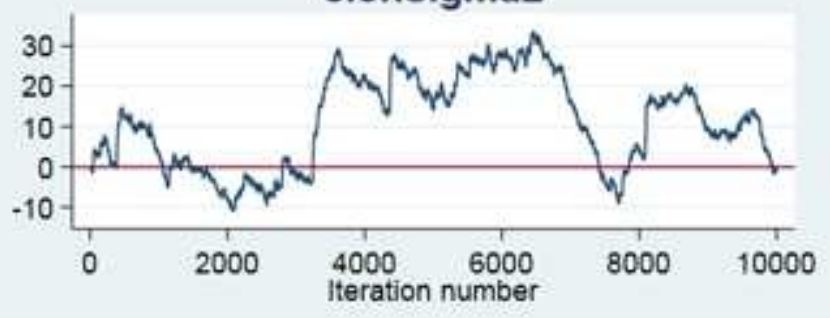

Figure 2 
The CUSUM plot of the parameters

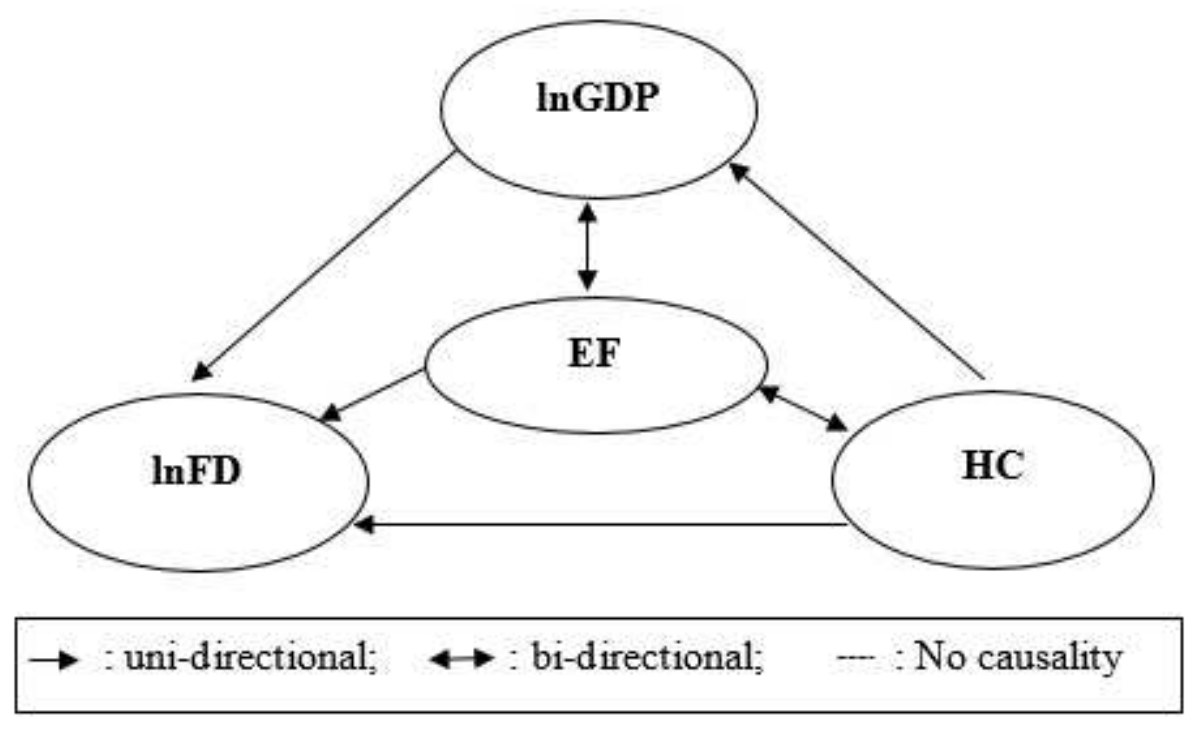

Figure 3

Plots of the causality test 